\title{
A kindergarten teacher bringing science to a community
}

\author{
Becky Theis ${ }^{1}$, Ed Galindo², and Tod Shockey ${ }^{3}$ \\ ${ }^{1}$ Lakeview Elementary School, Gillette, Wyoming, USA \\ 2,Aquaculture Research Institute, University of Idaho, Moscow, USA \\ ${ }^{3}$ Curriculum \& Instruction, University of Toledo, Toledo, USA \\ For correspondence: todshockey@gmail.com
}

\begin{abstract}
:
The National Aeronautical and Space Administration (NASA) sponsored professional development of educators in the NASA Summer of Innovation (SOI) program. The Idaho, Montana, and Utah (IMU-SOI) program worked with educators and students from thirteen Native American communities. The summer sessions were focused on problem based learning and engaging middle school youngsters in NASA and STEM curriculum. This paper describes the effort of one kindergarten teacher to bring a science club to her elementary school and how the local community embraced and supported the club.
\end{abstract}

Keywords: professional development, science club, elementary school science

\section{Introduction}

During a summer science education professional development program one reluctant kindergarten teacher realized how engaging science can be and reflected on the way science is often taught and took it upon herself to impact change at her local school. At the conclusion of the week long event, this teacher returned to her local school and a new principal and asked for support for a science club in their elementary school. After the new principal got acquinted with his new school he offered support for the first ever science club. With her building leadership support and a direct link to the higher education faculty that conducted the summer professional development, resources were gathered, students recruited, and a science club based on project based learning emerged. The initial student recruitment of over fifty students, from a student body of approximately 400, was enough for the principal to offer financial support for resources, but also support for another interested teacher to participate. After one semester the Science Club grew to 120 students, over a fourth of the student population in this $\mathrm{k}-6$ elementary school.

Initial Club Structure \& Local Support With the initiation of the science club the teachers needed a structure to support their students and also to make the time allotment manageable. Science Club met after school for 90 minutes. For each month the teachers developed one session that was offerred twice per month, twenty-five students were permitted to attend a session. As the club developed momentum financial resources from an Exxon Foundation grant allowed the purchase of four Lego Robotic Kits (part of the IMU-SOI professional development) and the IMU-SOI sent over the materials for the NASA paper rocket experiments. Through word of mouth, community members became aware of the new Science Club resulting in a local retired electrical engineer volunteering his time to introduce students to electrical circuits, a civil engineer to work with students in developing structures to support heavy loads (a set of encyclopedias) and the local Audubon Society to explore the biodiversity of a pond across the street from the school. The culminating experience for the first semester of the science club was attendance in Cape Canaveral Florida of a NASA Space Shuttle Launch. 
30 Minutes to Win It Engaging elementary school students in exciting hands-on activities becomes a bit easier when the venue is a spin-off of a popular television show. This theme begins with an introduction to that sessions activity, dispersal of materials, and then 30 minutes for teams to perform the activity. After the challenge is complete and projects evaluated there is a whole group debriefing. Science Club members have used this theme to build the tallest free standing structure with only paper and tape, to build balloon fired rockets, and a free standing structure that would support the load of a set of encyclopedias. For the support challenge three teams constructed structures that held the entire set of encyclopedias as well as the Index volume.

Paper Rockets A favorite NASA activity is the building of paper rockets that are launched using an air chamber constructed of pvc pipe and pressurized with a bicylce tire pump. Students construct personalized rockets from a sheet of paper. Components of the rockets include fins, a body, and a nose cone. Typically students use an 8.5 by 11 inch sheet of paper, so their rocket body is usually one of these dimensions. The number of fins attached to the base of the rocket is determined by the student as is the size of the nose cone. The final rocket is taped together, oftentimes personalized on the outside with coloring and then placed on the launch pad for launch. The rocket launch was the last school activity for the Science Club prior to the Florida trip. The teachers were anxious that the NASA trip would be the incentive for the following years science club enrollment. The anxiety was alleviated when students signed up asking when do we get to do the rockets?

Management To accomodate so many students, the teachers have broken the large group into four cohorts. Once a month a different assigned group of students meets to participate in an activity. Each cohort is a purposeful group of kindergarten through sixth grade students. Older students are paired with younger students to serve as mentors during activities. Younger students teach the older students classroom expectations as the club meets in the kindergarten classroom. Each after school session begins with a snack. When the teacher claps her hands, students are expected to repeat the clapping and then focus their attention on the teacher, the kindergartners and younger students make sure the older students focus during this instance. The lead teacher has two middle school age children that serve as support during the science club meetings. This dynamic of children leading children supports a learning environment of engagement.

Polymers Investigating polymers was the opening science club session for the 2011-2012 school year. Here we describe the session. The session opened with attendance and introductions, including myself, while students were having an after school snack. Mrs. T. then shared an overview of what science club was going to do and then opened with an introduction to polymers.

Mrs. T. initiated the idea of polymers with her club by asking them what they thought the word meant, see Figure 1. There were many ideas shared and in the background she had a prepared slide on the wall, but the definition was not given on the slide. After hearing the students ideas she shared that this was new science for herself, but with the visual aid of the slide she showed the students how polymer is defined and some examples. This led to her daughter taking over and demonstrating the first polymer experiment, piercing a balloon without bursting it. Her daughter modeled how the students would first use a marker and put dots on their deflated balloon. When this was done students then were shown how they would blow up the balloon to capacity and then release about half the air and tie off the balloon. Mrs. T. asked the students what would happen to the dots once the balloon was inflated and many thought the dots would expand as the balloon expanded. 


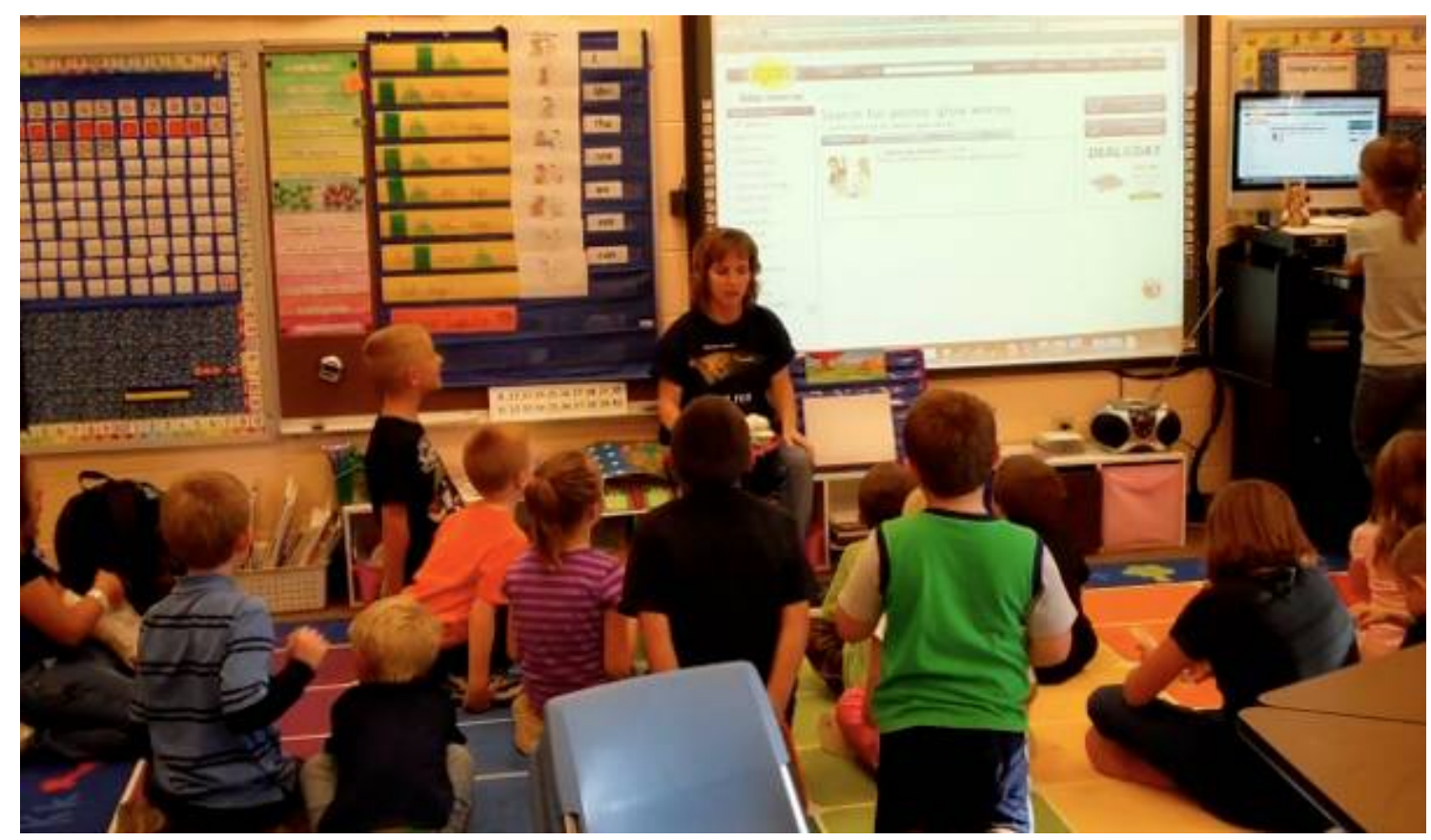

Figure 1. Talking About Polymers

It was interesting that dots on the balloon surface were difficult to see as they expanded so much. Once dots were identified Mrs. T. initiated a series of questions about the tightness of the balloon's surface on the outside edge and on the ends of the balloon. By looking at the dots students were able to recognize that the end dots were more visible as the balloon was not stretched to capacity there as opposed to the outside edges. Once there was general agreement about this idea Mrs. T.'s daughter then demonstrated how to push a wooden skewer through the balloon end to end without bursting the balloon. Before she proceeded though she dipped the skewer in some vegetable oil and that led to a new round of questions. There seemed to be consensus that the oil on the skewer would "seal" the hole if indeed the balloon did not burst. The balloon did not burst as Mrs. T.'s daughter modeled the experiment perfectly. There were some very impressed science club members as they watched this "magic."

Students then paired up, older child with younger child, found a workspace at a desk and proceeded to attempt the experiment. Mrs. T. let everyone know that she didn't like the sound of bursting balloons and surprisingly only a couple of student pairs burst their balloon. With slow twisting motions each group ultimately realized success in skewering a balloon without bursting it. Mrs. L. was quick to realize that one student was spectating and she quickly got his attention and a balloon and she paired up with him to make sure he had the experience. Many students extended the activity by withdrawing their skewer to watch if the balloon would fail, in most cases the balloon held its' air with a very slow leak.

This was very engaging for the students and as they were settling back Mrs. T. brought them all back together to focus more on their development of what a polymer was. This discussion was aided with illustrations of what a polymer might look like while at rest, imagine string laying on a surface wadded together and another illustration of the polymer when stretched out, grabbing the wad of string and straightening out strands. As students were continuing making their own meaning of the word polymer Mrs. T.'s children were in the back putting together the ingredients for the next experiment, Atomic Glow Worms.

Just the name created excitement for the children and when the ingredients were brought to a central table for distribution many of the students could not resist getting up to check out the "stuff." The two ingredients for the glow worms were a salt-water solution, not table salt, and some "worm slime" made from seaweed with a fluorescent die injected. Mrs. T. explained that when the slime was 
introduced into the salt solution the chloride in the salt solution would bind the slime together to make glowworms. This was really exciting for the club members when they watched the demonstration. Staying in their same groups, each pair then moved to a workspace at a desktop to create their own worms.

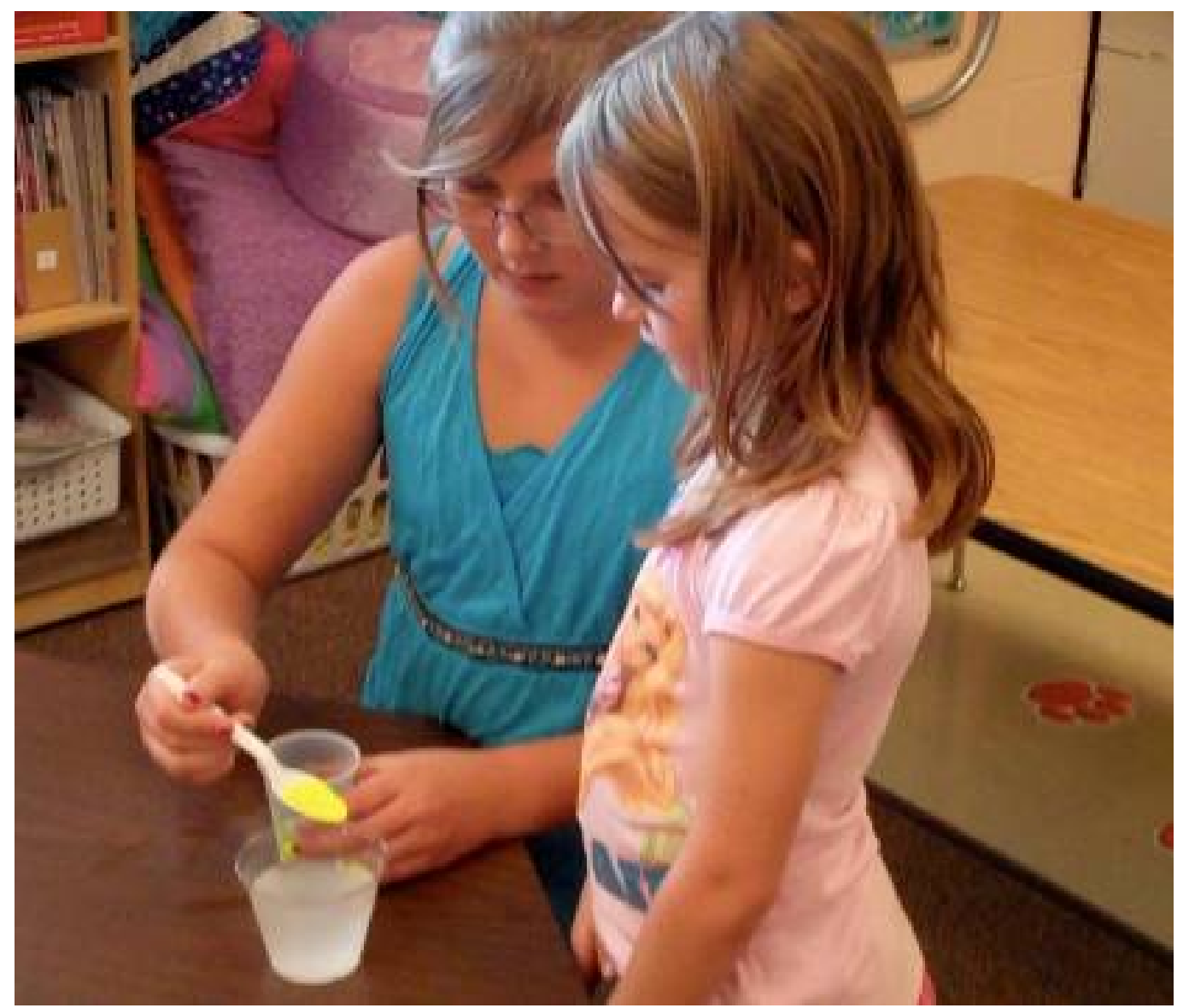

Figure 2. Creating Glow Worms 


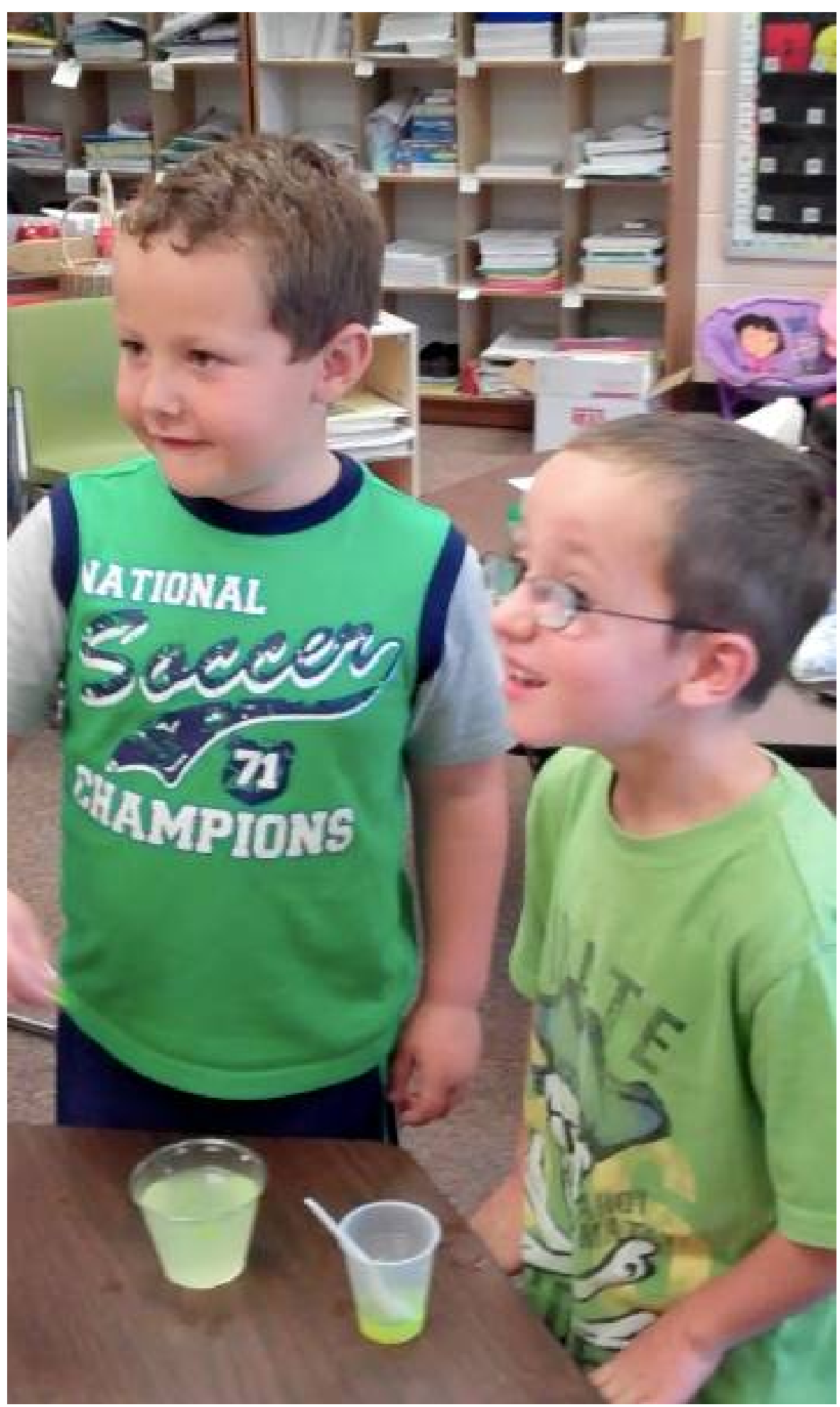

Figure 3. Waiting for Glow Worms to Grow

Students had two cups, one with slime and one with salt solution. In the slime cup they had a spoon that they used to introduce the slime into the salt solution. If the student dumped the slime in as a lump then got a ball that got firmer the longer it saturated chloride. If they allowed the slime to slowly run off their spoon then the got a glowworm. Of course each student was reaching into the cup and playing with the slime, as it became either a worm or ball. The giggling and excitement was infectious. Mrs. T. had little light fobs of black light, so groups went into the bathroom without the overhead 
lights on and had a chance to shine the black light into their glowing goo. "Dude that was awesome!" was one students' cry as he and his partner left the lavatory, see Figure 4

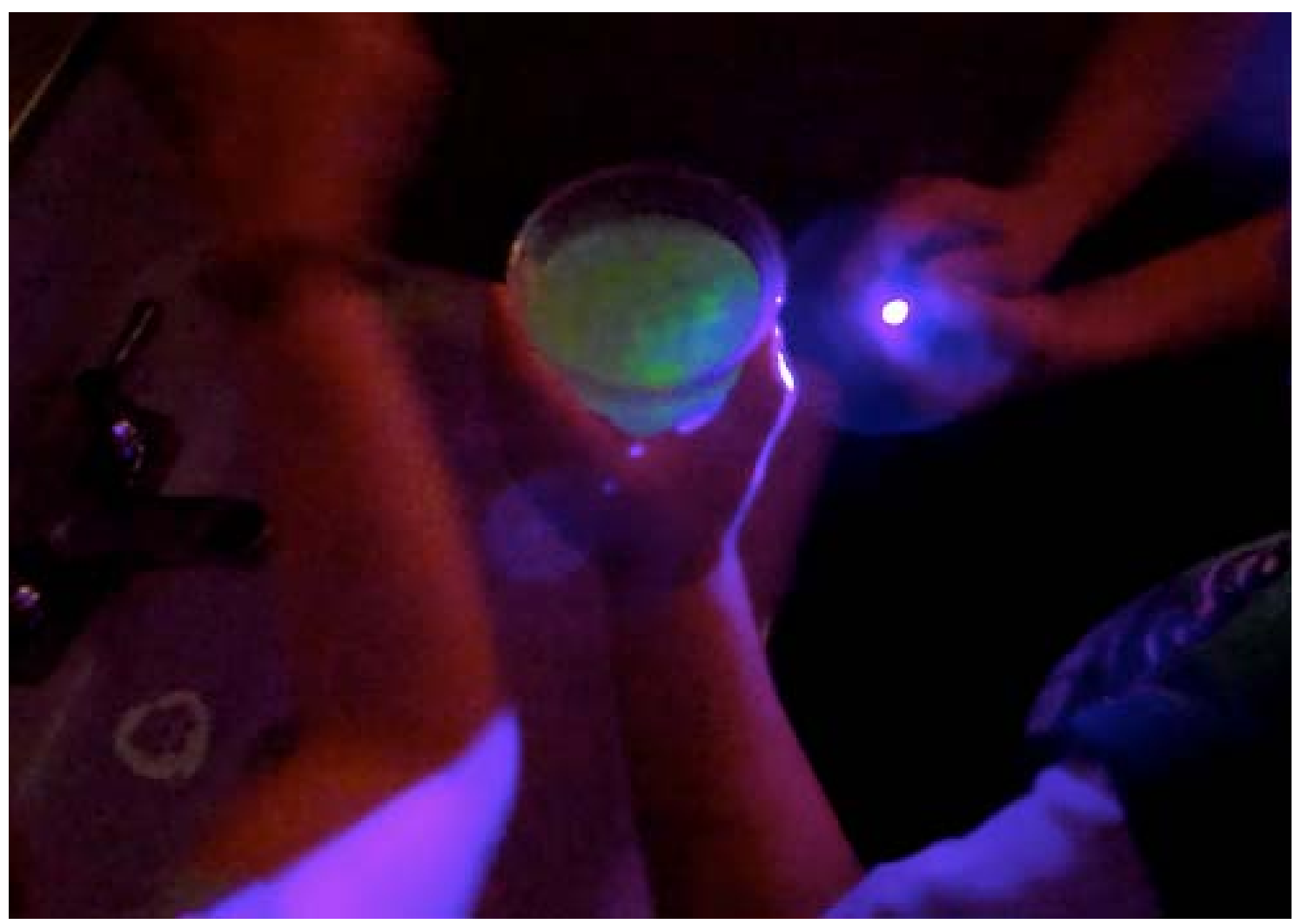

Figure 4. Watching Glow Worms Glow

There was plenty of time for student to play with their respective gooey mess and the excitement level in the club just kept rising. Management of the students was not an issue as the activity and the excitement kept each child engaged. All the club members were given a zip lock bag to put their respective glow worms in to take home "my mom is going to freak out" was one child's response when he had his glow worm in his bag. All of the groups accepted their respective responsibility for cleaning their work spaces and helping to pick up the classroom. Once all the clean up was accomplished there was still enough time for a game. The teachers did a remarkable job of managing their time and keeping the activities flowing.

Concluding Remarks Science should not be constrained to the words on the page of a textbook. Too frequently curriculum is crammed with preparation for a states' exit examination which doesn't allow enough inquiry, hands-on activities. When students are engaged, classroom management dissipates. In the model shown, all the children have roles, either mentoring younger students, sharing classroom expectations with older students, and everyone pitches in when science club concludes.

The Wyoming standards for science education are easily recognized when students are engaged in inquiry based activities. All science club members are experiencing science as inquiry. These educators understand that science is a dynamic process; concepts and content are best learned through inquiry and investigation as stated in the Wyoming Science Content and Performance Standards.

Professional development should not be a one time occurrence and an element of sustainability must be a requirement. The summer session that this educator attended is now three years past. She maintains her correspondence with the faculty from higher education who embrace the opportunity to work with and support her interactions with elementary students. Higher education must have open communication with classroom teachers. While university faculty do not frequently have contact with 
school age children, they must maintain contact with teachers and provide intellectual and material support for the education of our youth.

These educators are making a difference, science is coming to life and children are expected to explore and get messy. During the attendance for the polymer meeting, one young child was hiding in her group of peers. When roll was concluded the teacher asked if anyones name had not been called. Sheepishly this child raised her hand. The teacher immediately recognized her by name and told her that her science club meeting was the previous one and she needed to catch the bus home. The child resisted in the kindest way. As the child was being escorted to the bus zone she could be heard saying how much she loved being at science club doing all the neat things. There is no better testament for allowing students to engage their curiousity.

\section{References}

National Areonautical and Space Administration, (2010)"Summer of Innovation" http://www.nasa.gov/offices/education/programs/national/summer/home/index.html, (accessed June 2013) Wyoming Science Content and Performance Standards, (2008),

http:/ / www.google.com/url?sa=t\&rct=j\&q=\&esrc=s\&source=web\&cd=2\&ved=0CDEQFjAB\&url=http $\% 3 \mathrm{~A} \% 2 \mathrm{~F} \% 2 \mathrm{Fedu} . \mathrm{w}$ yoming.gov $\% 2 \mathrm{Fsf}-$

docs\%2Fpublications\%2FStandards_2008_Science_PDF.pdf\&ei=B5K4UaAIhIbIAYmagbgF\&usg=AFQjCNFZA17xFY1GdWo pni6yQdNe2aaaAQ\&bvm=bv.47810305,d.aWc (accessed June 2013) 